\title{
Período Crítico de Interferência das Plantas Daninhas na Cultura do Feij Oeiro-Comum em Sistema de Semeadura Direta
}

\author{
Critical Period of Weed Interference in the Common Bean Crop Under Direct Seeding System
}

KOZLOWSKI, L.A. ${ }^{2}$, RONZELLI JÚNIOR, P. ${ }^{3}$, PURISSIMO, C. ${ }^{4}$, DAROS, E. ${ }^{3}$ e KOEHLER, H.S. ${ }^{5}$

\begin{abstract}
RESUMO - No ano agrícola 1996/97 foi conduzido, na Fazenda-Escola da Universidade Estadual de Ponta Grossa, em Ponta Grossa-PR, um experimento a campo com o objetivo de determinar o período crítico de prevenção da interferência das plantas daninhas sobre a cultura do feijoeirocomum (Phaseolus vulgaris), em sistema de semeadura direta, associando esse período com a fenologia da planta. O delineamento experimental utilizado foi o de blocos ao acaso em arranjo fatorial $2 \times 8$, com quatro repetições. Os 16 tratamentos testados foram resultados da combinação de dois conjuntos de tratamentos de interferência das plantas daninhas: (1) inicialmente em convivência com as plantas daninhas (2) inicialmente sem convivência com as plantas daninhas, em sete estádios fenológicos do feijoeiro - V2, V3, V4, R5, R6, R7 e R8 e uma testemunha em convivência durante todo o ciclo da cultura. O experimento foi instalado em uma área há oito anos sob plantio direto, com semeadura realizada de acordo com a tecnologia recomendada para a cultura, com adubações no sulco e em cobertura e tratamentos fitossanitários, para que os feijoeiros se desenvolvessem normalmente. O período crítico de prevenção da interferência ocorreu entre os estádios fenológicos V4 e R6, e a interferência das plantas daninhas durante todo o ciclo reduziu em média $71 \%$ o rendimento de grãos dos feijoeiros. Com relação à comunidade infestante, as dicotiledôneas representaram $61,3 \%$ das plantas daninhas, destacando-se as espécies Bidens pilosa e Richardia brasiliensis, com 30,6 e 16,6\%, respectivamente; já as monocotiledôneas representaram 38,7\% da comunidade infestante, com destaque para as espécies Digitaria horizontalis e Brachiaria plantaginea, com 23,6 e $14,3 \%$, respectivamente.
\end{abstract}

Palavras-chave: feijoeiro, fenologia, interferência, período crítico, plantio direto.

\begin{abstract}
A field experiment was carried out at the Training Farm of Ponta Grossa State University, in Ponta Grossa-PR, Brazil, during the 1996/1997 growing season to determine the critical period of weed interference in the common bean under direct seeding system, associated with the phenological stage of the common bean growth. The experimental design was a randomized complete block arranged in a $2 \times 8$ factorial, with four replications. The 16 treatments tested resulted from a combination of two groups of weed interference treatments : (a) relative weedy period, and (b) relative weed-free period, in seven physiological stages of bean growth: $V 2, V 3, V 4, R 5, R 6, R 7$ and R8, and a check plot with the crop in coexistence with the weeds. The experiment was carried out on an area 8 years under direct seeding system. Sowing, fertilization, and insect and disease control were performed according to the technology recommended for the crop. The weed interference critical period occurred between the V4 and R6 phenological stages of growth, and bean yield was reduced in $71 \%$ when the crop was maintained in coexistence with the weeds during all the crop cycle. Regarding weed composition, the dicotyledons class of weed represented $61.3 \%$, being Bidens pilosa and Richardia brasiliensis the most prevalent, with $30.6 \%$ and $16.6 \%$, respectively. Monocotyledons represented $38.7 \%$, and Digitaria horizontalis and Brachiaria plantaginea, were the most prevalent, with $23.6 \%$ and $14.3 \%$, respectively.
\end{abstract}

Key words: bean plant, phenology, interference, critical period, no-till.

1 Recebido para publicação em 26/7/2001 e na forma revisada em 7/8/2002.

Parte da dissertação de mestrado do primeiro autor apresentada ao DFF/UFPR, Curitiba-PR.

2 Professor Adjunto, M.S., Pontifícia Universidade Católica do Paraná, 80215-901Curitiba-PR; ${ }^{3}$ Professor Adjunto, Dr., Universidade Federal do Paraná, 81531-990 Curitiba-PR. ${ }^{4}$ Professor Adjunto, Ph.D., Universidade Estadual de Ponta Grossa, Ponta Grossa-PR. ${ }^{5}$ Professor Adjunto, M.S., Universidade Federal do Paraná.

Planta Daninha, Viçosa-MG, v.20, n.2, p.213-220, 2002 


\section{INTRODUÇÃO}

As culturas agrícolas estão sujeitas aos fatores ambientais, de natureza biótica ou abiótica, que direta ou indiretamente influenciam não só a sua produtividade biológica, como também o sistema de produção empregado. Nos ecossistemas agrícolas, a presença de plantas daninhas condiciona diversos fatores bióticos atuantes sobre as plantas cultivadas, que vão interferir no seu crescimento, seu desenvolvimento e na sua produtividade, cujos efeitos negativos observados estão ligados à presença das plantas daninhas no ambiente agrícola. Esse efeito é denominado interferência (Pitelli, 1985).

A intensidade das interferências, normalmente, é avaliada por meio de decréscimos de produção e/ou crescimento da planta cultivada, como conseqüência da competição pelos fatores de crescimento disponiveis no ambiente (água, luz, nutrientes e $\mathrm{CO}_{2}$ ), da liberação de substâncias alelopáticas e, de forma indireta, pelo fato de as plantas daninhas atuarem como hospedeiras de pragas, doenças e nematóides, além de dificultarem a realização dos tratos culturais e da colheita (Chisaka, 1977). Dentre os componentes do conjunto de interferências, a competição e a alelopatia são os processos de maior significância e que ocorrem com maior freqüência, porém, devido à dificuldade de isolar os efeitos desses processos, tem-se procurado quantificar os efeitos do conjunto de interferências (Velini, 1997).

O grau de interferência normalmente é medido com relação à produção da planta cultivada e pode ser definido como a redução percentual da produção econômica de determinada cultura, provocada pela interferência da comunidade infestante (Pitelli, 1985). O grau de interferência depende de características da cultura, como variedade ou espécie, espaçamento e densidade de plantio; de características da comunidade infestante, como composição específica, densidade e distribuição; de características do ambiente, referentes às condições edáficas, climáticas e de manejo do sistema agrícola; e da época e duração do período de convivência entre planta daninha e cultura (Bleasdale, 1960).

De todos os fatores que influenciam o grau de interferência, o mais importante é, talvez, o período em que a comunidade infestante e as plantas cultivadas estão disputando os recursos do meio. De modo geral, pode-se dizer que, quanto maior for o período de convivência cultura - comunidade infestante, maior será o grau de interferência. No entanto, isso não é totalmente válido, pois depende do momento do ciclo da cultura em que esse período de convivência ocorre (Pitelli, 1985).

Quanto aos períodos de convivência entre as plantas daninhas e cultivadas, destacamse três: período total de prevenção da interferência (PTPI), período de pré-interferência ou anterior à interferência (PAI) e período crítico de prevenção da interferência (PCPI). O estudo desses períodos determina o período em que efetivamente os métodos de controle devem atuar (Pitelli \& Durigan, 1984).

O período crítico de competição é o período de tempo em que medidas de controle são necessárias para evitar a continuidade da interferência entre a cultura e as plantas daninhas, evitando perdas no rendimento. Entretanto, esse período deve ser considerado como um estádio de desenvolvimento da cultura em relação às plantas daninhas e não como um período de tempo definido (Radosevich \& Holt, 1984); assim, o uso de uma escala baseada nas mudanças morfológicas e nos eventos fisiológicos que se sucedem no ciclo de vida da planta oferece maior segurança e precisão nas ações de manejo (Fancelli \& Dourado Neto, 2000).

Na cultura do feijoeiro, vários autores estudaram o período crítico de competição, entre eles Blackshaw (1991), Cerna (1983), Kramm et al. (1990), Neary \& Majek (1990), Rodriguez \& Faiguenbaum (1985) e Tivelli et al. (1987), porém esses trabalhos forneceram informações do período crítico de competição com base em um período de tempo definido, ou seja, dias após a emergência, ao passo que poucos autores, como Ngouajio et al. (1997) e Woolley et al. (1993), estudaram o período crítico de competição baseado em uma escala fenológica da cultura em relação às plantas daninhas.

O presente trabalho teve como objetivo determinar o período crítico de prevenção da interferência das plantas daninhas sobre a cultura do feijoeiro, em sistema de semeadura direta, associando esse período com a fenologia da planta. 


\section{MATERIAL E MÉTODOS}

O trabalho experimental de campo foi instalado e conduzido no ano agrícola 1996/97 na Fazenda-Escola da Universidade Estadual de Ponta Grossa, em Ponta Grossa, Paraná. A região, segundo a classificação de Koëpen, apresenta clima do tipo Cfb e solo pertencente à unidade de mapeamento Latossolo VermelhoEscuro Distrófico, textura argilosa, relevo suave ondulado a plano.

O delineamento experimental utilizado foi o de blocos ao acaso com tratamentos em arranjo fatorial $2 \times 8$, com quatro repetições. Os 16 tratamentos testados e apresentados na Tabela 1 resultaram da combinação de dois modelos de interferência das plantas daninhas: (a) inicialmente sujo (S) e (b) inicialmente limpo (L), aplicados em sete estádios de desenvolvimento do feijoeiro: V2, V3, V4, R5, R6, R7 e R8, conforme apresentado na Tabela 2 e em uma testemunha (T).

O experimento foi instalado em uma área há oito anos sob semeadura direta, tendo o trigo como cultura anterior. A semeadura foi realizada em 30 de setembro e a emergência ocorreu em 7 de outubro de 1996. Foi utilizada a variedade de feijão 'FT Nobre', com hábito de crescimento indeterminado, tipo II, grupo comercial preto. Para a adubação de semeadura foram utilizados $350 \mathrm{~kg} \mathrm{ha}^{-1}$ do formulado 2-25-25, sendo feita mecanicamente no

Tabela 1 - Tratamentos utilizados no experimento, no ano agrícola de 1996/97, na Fazenda Escola/UEPG, em Ponta Grossa-PR

\begin{tabular}{|c|c|c|}
\hline \multirow{2}{*}{ Estádio } & \multicolumn{2}{|c|}{ Modelo de interferência } \\
\cline { 2 - 3 } & Sujo (S) $)^{\frac{1}{\prime}}$ & Limpo (L) $)^{2 /}$ \\
\hline V2 & V2S & V2L \\
V3 & V3S & V3L \\
V4 & V4S & V4L \\
R5 & R5S & R5L \\
R6 & R6S & R6L \\
R7 & R7S & R7L \\
R8 & R8S & R8L \\
Testemunha & TS & TL \\
\hline
\end{tabular}

1/ Inicialmente sujo (S) até o estádio aplicado, após o que o tratamento foi mantido no limpo até a colheita.

22/ Inicialmente limpo (L) até o estádio aplicado, após o que o tratamento foi mantido no sujo até a colheita. momento da semeadura, de forma que todos os tratamentos receberam a mesma adubação de semeadura, visando atender as exigências nutricionais do feijoeiro.

A parcela experimental foi composta por quatro linhas espaçadas entre si de $0,45 \mathrm{~m}$ com 7,0 m de comprimento, perfazendo $12,60 \mathrm{~m}^{2}$ de área total. Para fins de avaliação foram consideradas como área útil das parcelas experimentais as duas linhas centrais com 5,00 $\mathrm{m}$ de comprimento, desprezando-se $1,00 \mathrm{~m}$ a título de bordadura, na frente e no fundo de cada parcela, totalizando $4,50 \mathrm{~m}^{2}$, onde foram feitas as avaliações, na colheita, do rendimento do feijoeiro.

Foram feitas a coleta, contagem e identificação das espécies de plantas daninhas presentes em uma área central de $0,5 \mathrm{~m}^{2}$, na área útil das parcelas inicialmente sujas, para determinação da composição específica da comunidade infestante, em porcentagem e densidade de indivíduos das populações de plantas daninhas presentes, corrigindo a densidade para número de plantas por $\mathrm{m}^{2}$, em cada um dos diferentes estádios de desenvolvimento do feijoeiro - V2, V3, V4, R5, R6, R7 e R8 - e nas testemunhas sujas; neste caso, a coleta, a contagem e a identificação foram feitas junto com a maturação e colheita dos feijoeiros. Posteriormente foi feita a secagem das plantas daninhas em estufa de circulação forçada de ar a $70^{\circ} \mathrm{C}$ até peso constante, para determinação da biomassa epígea seca.

Tabela 2 - Estádios de desenvolvimento do feijoeiro (Fernandez et al., 1982)

\begin{tabular}{|c|l|}
\hline Estádio & \multicolumn{1}{|c|}{${\text { Descrição }{ }^{\underline{1}}}^{\prime}$} \\
\hline V0 & Germinação \\
V1 & Emergência \\
V2 & Folhas primárias abertas \\
V3 & Primeira folha trifoliolada aberta e plana \\
V4 & Terceira folha trifoliolada aberta e plana \\
R5 & Primeiro rácimo floral nos nós inferiores - Pré-floração \\
R6 & Primeira flor aberta - Floração \\
R7 & Formação de vagem \\
R8 & Enchimento de grãos \\
R9 & Maturação \\
\hline
\end{tabular}

1/ A caracterização do estádio é definida quando $50 \%$ ou mais plantas da parcela ou amostra apresentam as características descritas. 
Na determinação do período crítico de prevenção da interferência foram usados dois modelos de interferência: (a) inicialmente sujo e (b) inicialmente limpo. No modelo inicialmente sujo visou-se a determinação do período anterior à interferência (PAI), em que as parcelas foram mantidas com a presença das plantas daninhas com o feijoeiro desde a sua emergência até que os diferentes estádios de desenvolvimento (V2, V3, V4, R5, R6, R7 e R8) fossem alcançados. Nesse momento foi feito o controle químico com fluazifop-p-butil + fomesafen na dose equivalente a 1,0 $\mathrm{L} \mathrm{ha}^{-1}$ do produto comercial, aplicado em pós-emergência da cultura e das plantas daninhas, com equipamento de precisão pressurizado a $\mathrm{CO}_{2}$ equipado com barra com quatro bicos leque tipo XR 110.02 VS, espaçados $0,50 \mathrm{~cm}$ entre si, com volume de aplicação de $120 \mathrm{~L} \mathrm{ha}^{-1}$; a partir de cada estádio de desenvolvimento a cultura foi mantida no limpo por meio do controle químico entrelinhas com o paraquat a 30\% de concentração, utilizando o aplicador manual de cordão embebido para a capina química nas entrelinhas do feijoeiro, tantas vezes quantas necessárias para se manter a cultura totalmente no limpo. Nesse modelo foi mantida uma testemunha sempre suja até a maturação do feijoeiro.

No modelo inicialmente limpo visou-se a determinação do período total de prevenção da interferência (PTPI), em que se manteve a ausência das plantas daninhas nas parcelas desde a emergência do feijoeiro até os diferentes estádios de desenvolvimento (V2, V3, V4, R5, R6, R7 e R8), sendo o controle feito quimicamente com paraquat a 30\% de concentração, utilizando o aplicador manual de cordão embebido para a capina química nas entrelinhas do feijoeiro, tantas vezes quantas necessárias para se manter a cultura totalmente no limpo, sendo posteriormente as parcelas mantidas com a presença das plantas daninhas, do estádio em questão até a maturação do feijoeiro. Neste modelo foi mantida uma testemunha sempre limpa, na qual foi feita uma aplicação de fluazifop-p-butil + fomesafen na dose equivalente a 1,0 L ha-1 do produto comercial assim que emergiram as primeiras plantas daninhas na cultura (estádio V2), usando-se equipamento de precisão pressurizado a $\mathrm{CO}_{2}$ equipado com barra com quatro bicos leque tipo $\mathrm{XR}$ $110.02 \mathrm{VS}$, espaçados $0,50 \mathrm{~cm}$ entre si, com volume de aplicação de $120 \mathrm{~L} \mathrm{ha}^{-1}$ e capina química entrelinhas com o aplicador manual de cordão embebido, usando-se paraquat a $30 \%$ de concentração, até a colheita do feijão.

Para a determinação do período crítico de prevenção da interferência, os dados dos rendimentos obtidos nos diferentes estádios fenológicos, em ambos os modelos de interferência, foram ajustados a um modelo de regressão nãolinear, por meio do programa TableCurve, usando a equação logística:

$$
y=a+\frac{b}{\left[1+\left(\frac{x}{c}\right)^{d}\right]}
$$

em que $y$ é rendimento de grãos, $x$ é dias após a emergência dos feijoeiros e $a, b, c$ e $d$ são coeficientes, de modo que $a$ é o rendimento mínimo, no início do ensaio para inicialmente limpo e no final do ensaio para inicialmente sujo, $b$ é a diferença entre o rendimento máximo e o mínimo, $c$ é o número de dias em que ocorreu 50\% de redução no rendimento máximo e $d$ é a declividade da curva.

O início do período crítico de prevenção da interferência, identificado pelo final do período anterior à interferência (PAI) no modelo inicialmente sujo, foi calculado subtraindo-se a diferença mínima significativa (DMS a 5\% de probabilidade) da média do rendimento máximo. O resultado foi substituído em $y$ da equação logística, obtendo-se assim o valor de $x$, que identifica o número de dias após a emergência do feijoeiro em que iniciou o período crítico de prevenção da interferência.

O final do período crítico de prevenção da interferência, coincidente com o final do período total de prevenção da interferência (PTPI) no modelo inicialmente limpo, foi calculado subtraindo-se a diferença mínima significativa (DMS a 5\% de probabilidade) da média do rendimento máximo. O resultado foi substituído em $y$ da equação logística, obtendo-se assim o valor de $x$, que identifica o número de dias após a emergência do feijoeiro em que terminou o período crítico de prevenção da interferência.

Os dados de massa seca das plantas daninhas, folhas largas e estreitas foram transformados em $\log x$ para uniformização dos valores, 
sendo posteriormente ajustados a um modelo de regressão não-linear, por meio do programa TableCurve, usando a equação logística para descrever a curva de acúmulo da matéria seca das infestantes.

\section{RESULTADOS E DISCUSSÃO}

Pode-se observar, na Tabela 3, os dias após a emergência do feijoeiro e os dias do calendário em que foram caracterizados os sete estádios fenológicos (V2 a R8) e as testemunhas, suja e limpa.

Tabela 3 - Dias após a emergência (DAE) do feijoeiro e do calendário (DC) em que os sete estádios fenológicos (V2 a R8) e as testemunhas (T), suja e limpa, foram caracterizados. Fazenda-Escola/UEPG, Ponta GrossaPR. 1996/97

\begin{tabular}{|c|c|c|}
\hline Estádio & DAE & DC \\
\hline V2 & 7 & $14 / 10$ \\
V3 & 22 & $29 / 10$ \\
V4 & 28 & $04 / 11$ \\
R5 & 42 & $18 / 11$ \\
R6 & 49 & $25 / 11$ \\
R7 & 63 & $09 / 12$ \\
R8 & 77 & $23 / 12$ \\
T & 99 & $14 / 01$ \\
\hline
\end{tabular}

Os resultados de produção do feijoeiro podem ser analisados observando-se a Figura 1, onde, comparando as produções obtidas na ausência total das plantas daninhas (testemunha limpa) com as obtidas na presença destas durante todo o ciclo (testemunha suja), se verifica que a redução no rendimento foi de $71 \%$. A produção do feijoeiro obtida na ausência das plantas daninhas durante todo o ciclo foi de $2.467 \mathrm{~kg} \mathrm{ha}^{-1}$, sendo reduzida para $711 \mathrm{~kg} \mathrm{ha}^{-1}$ quando ocorreu a presença das infestantes durante todo o ciclo. Esses resultados concordam com trabalhos anteriores, em que se constatou a redução no rendimento de grãos devido à interferência das plantas daninhas (Blackshaw, 1991; Kranz et al., 1982; Malik et al., 1993; Neary \& Mazek, 1990; Willian, 1973; Zollinger \& Kells, 1993).

Na Figura 1 estão representadas as duas curvas ajustadas pela equação de regressão não-linear, uma representando os rendimentos obtidos no modelo inicialmente sujo (sujoajs), que foi o período anterior à interferência (PAI), e a outra representando os rendimentos obtidos no modelo inicialmente limpo (limpoajs), que é o período total de prevenção da interferência (PTPI); os pontos, sujo e limpo, representam os rendimentos médios obtidos. Comparando as médias dos tratamentos, pelo teste DMS a $5 \%$ de probabilidade, dentro do mesmo modelo de interferência, sujo ou limpo, observa-se que o valor da diferença mínima significativa $(\mathrm{P}<0,05)$ é de $406 \mathrm{~kg}$.ha ${ }^{-1}$, o que permite verificar que rendimentos iguais ou superiores a $1.769 \mathrm{~kg} \mathrm{ha}^{-1}(2175-406)$ e $2.061 \mathrm{~kg} \mathrm{ha}^{-1}(2467$ - 406) para os modelos sujo e limpo, respectivamente, não diferem significativamente; com esses rendimentos é possivel calcular o período crítico de prevenção da interferência (PCPI), de acordo com as equações a seguir.

Para o modelo inicialmente sujo:

$$
1769=848,5+\frac{1280}{\left[1+\left(\frac{x}{42,6}\right)^{5,43}\right]}
$$

em que $x$ corresponde a quando, em dias, terminam o PAI ou inicia o PCPI.

Para o modelo inicialmente limpo:

$$
2061=202,7+\frac{6684,6}{\left[1+\left(\frac{x}{473}\right)^{-0,45}\right]}
$$

em que $x$ corresponde a quando, em dias, termina o PTPI e o PCPI.

Os valores de $x$ correspondem a 35,8 e 57,5 dias, para sujo e limpo, respectivamente, de modo que 35,8 dias correspondem a um período intermediário entre os estádios fenológicos V4, que ocorreu aos 28 dias após a emergência, e R5, que ocorreu aos 42 dias após a emergência do feijoeiro, enquanto 57,5 dias correspondem a um período intermediário entre os estádios fenológicos R6, que ocorreu aos 49 dias após a emergência, e R7, que ocorreu aos 63 dias após a emergência do feijoeiro, porém ainda caracterizando os estádios V4 e R6. Verificou-se, assim, que o período crítico de prevenção da interferência (PCPI) está entre os estádios fenológicos V4 (35,8 dias) e R6 
(57,5 dias); para obter os máximos rendimentos é necessário que a cultura fique na ausência das plantas daninhas durante esse período de tempo. Resultados semelhantes foram obtidos em outros trabalhos, em que se constatou que o período crítico de prevenção da interferência ocorreu entre os estádios fenológicos da segunda folha trifoliolada e as primeiras flores do feijoeiro, ou seja, estádio R6 (Woolley et al., 1993), e entre os estádios V3, primeira folha trifoliolada, e R8, enchimento de grãos (Ngouajio et al., 1997).

Na Figura 2 estão representadas as duas curvas ajustadas pela equação de regressão não-linear, uma representando a massa seca das plantas daninhas de folhas largas (mspdflajs) e a outra a massa seca das plantas daninhas de folhas estreitas (mspdfeajs); os pontos representam a massa seca das plantas daninhas, folhas largas (mspdfl) e estreitas (mspdfe), obtidas nas parcelas experimentais. Verifica-se que o aumento da massa seca das plantas daninhas, folhas largas e estreitas, foi progressivo entre os estádios V2 e R8 até a testemunha suja, embora as maiores densidades fossem observadas nos estádios V3, V4 e R5, com média de 1.366 plantas $\mathrm{m}^{-2}$, conforme se pode observar na Tabela 4 . No entanto, as maiores densidades nesses estádios caracterizam-se por

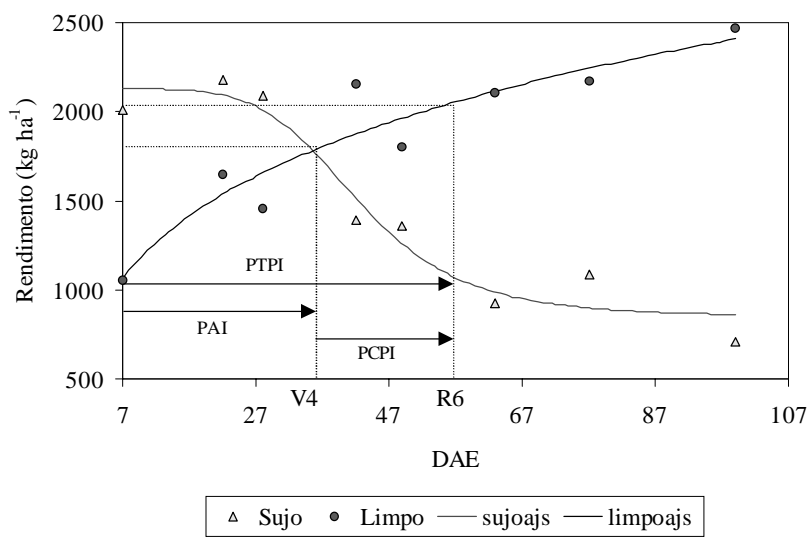

Figura 1 - Rendimentos, em $\mathrm{kg} \mathrm{ha}^{-1}$, obtidos nas parcelas experimentais (sujo e limpo) e ajustados pela regressão não-linear (sujoajs e limpoajs) em dois modelos de interferência de plantas daninhas, inicialmente sujo e inicialmente limpo, sobre a cultura do feijoeiro, variedade "FT Nobre", observados em dias após a emergência (DAE). Fazenda-Escola/UEPG. Ponta Grossa-PR. 1996/97. plantas de diferentes tamanhos e estádios de desenvolvimento, devido aos vários fluxos de emergência; à medida que aumentaram a densidade e o crescimento das plantas daninhas, especialmente daquelas que germinaram e emergiram no início do ciclo do feijoeiro, intensificou-se a competição interespecífica e intra-específica, de modo que as plantas daninhas mais altas e desenvolvidas tornaram-se dominantes, ao passo que as menores foram suprimidas ou morreram, justificando assim a redução da densidade das infestantes com o aumento da massa seca das plantas daninhas nos estádios de desenvolvimento finais do feijoeiro (Radosevich \& Holt, 1984).

A maior densidade, 1.658 plantas $\mathrm{m}^{-2}$, ocorreu no estádio V4, início do período crítico de prevenção da interferência. Observa-se na Tabela 5 que as dicotiledôneas representam $61,30 \%$ da comunidade infestante, destacandose as espécies Bidens pilosa e Richardia brasiliensis, com 30,60 e 16,60\%, respectivamente, e as monocotiledôneas, com 38,70\% da comunidade infestante, com destaque para as espécies Digitaria horizontalis e Brachiaria plantaginea, com 23,60 e 14,30\%, respectivamente. Essas quatro espécies correspondem a $85,10 \%$ dos indivíduos da comunidade infestante.

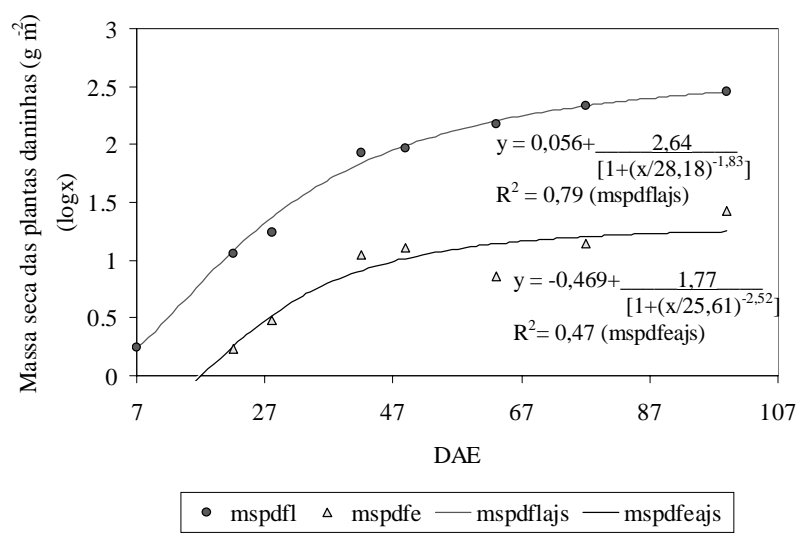

Figura 2 - Massa seca das plantas daninhas $\left(\mathrm{g} \mathrm{m}^{-2}\right)$, folhas largas (mspdfl) e estreitas (mspdfe), obtidas nas parcelas experimentais e ajustada pela regressão não-linear (mspdflajs e mspdfeajs), no modelo de interferência inicialmente sujo, sobre o feijoeiro, variedade "FT Nobre", observada em dias após a emergência (DAE). FazendaEscola/UEPG. Ponta Grossa-PR. 1996/97. 
Tabela 4 - Composição específica e densidade, em número de plantas por $\mathrm{m}^{2}$, das plantas daninhas, folhas largas e estreitas, presentes no modelo de interferência inicialmente sujo, na cultura do feijoeiro, variedade 'FT Nobre', em sete estádios fenológicos (V2 a R8) e em uma testemunha (T) suja. Fazenda-Escola/UEPG. Ponta Grossa-PR. 1996/97

\begin{tabular}{|c|c|c|c|c|c|c|c|c|}
\hline \multirow{2}{*}{ Composição Específica } & \multicolumn{7}{|c|}{ Estádio } & \multirow{2}{*}{$\mathrm{T}$} \\
\hline & $\mathrm{V} 2$ & V3 & V4 & R5 & R6 & R7 & $\mathrm{R} 8$ & \\
\hline Bidens pilosa & 44 & 366 & 559 & 406 & 322 & 134 & 175 & 156 \\
\hline Sida rhombifolia & 20 & 89 & 95 & 90 & 36 & 66 & 35 & 13 \\
\hline Richardia brasiliensis & 62 & 250 & 277 & 223 & 77 & 184 & 92 & 15 \\
\hline Sonchus oleraceus & 1 & 0 & 1 & 0 & 1 & 0 & 0 & 1 \\
\hline Galinsoga parviflora & 18 & 9 & 31 & 46 & 89 & 68 & 0 & 4 \\
\hline Ipomea spp. & 1 & 2 & 6 & 0 & 0 & 0 & 1 & 0 \\
\hline Euphorbia heterophylla & 3 & 13 & 20 & 5 & 23 & 14 & 0 & 7 \\
\hline Raphanus raphanistrum & 3 & 4 & 70 & 31 & 15 & 1 & 13 & 1 \\
\hline Amaranthus retroflexus & 0 & 5 & 33 & 11 & 0 & 4 & 5 & 0 \\
\hline SUBTOTAL (1) & 152 & 738 & 1.092 & 812 & 563 & 471 & 321 & 197 \\
\hline Digitaria horizontalis & 53 & 527 & 20 & 159 & 233 & 154 & 128 & 155 \\
\hline Brachiaria plantaginea & 149 & 33 & 526 & 172 & 117 & 43 & 0 & 16 \\
\hline Eleusine indica & 0 & 0 & 20 & 0 & 28 & 14 & 0 & 1 \\
\hline SUBTOTAL (2) & 202 & 560 & 566 & 331 & 378 & 211 & 128 & 172 \\
\hline TOTAL $(1+2)$ & 354 & 1.298 & 1.658 & 1143 & 941 & 682 & 449 & 369 \\
\hline
\end{tabular}

Tabela 5 - Composição percentual das populações de plantas daninhas (\%), folhas largas e estreitas, presentes no modelo de interferência, inicialmente sujo, na cultura do feijoeiro, variedade 'FT Nobre', em sete estádios fenológicos (V2 a R8) e em uma testemunha (T) suja. Fazenda-Escola/UEPG. Ponta Grossa-PR. 1996/97

\begin{tabular}{|l|c|c|c|c|c|c|c|c|c|}
\hline \multirow{2}{*}{ Composição Específica } & \multicolumn{10}{c|}{ Estádio } & \multirow{2}{*}{ Média } \\
\cline { 2 - 10 } & $\mathrm{V} 2$ & $\mathrm{~V} 3$ & $\mathrm{~V} 4$ & $\mathrm{R} 5$ & $\mathrm{R} 6$ & $\mathrm{R} 7$ & $\mathrm{R} 8$ & $\mathrm{~T}$ & \\
\hline Bidens pilosa & 12,43 & 28,2 & 33,71 & 35,52 & 34,21 & 19,64 & 39,0 & 42,20 & 30,60 \\
Sida rhombifolia & 5,65 & 6,85 & 5,73 & 7,9 & 3,82 & 9,67 & 7,80 & 3,56 & 6,5 \\
Richardia brasiliensis & 17,50 & 19,26 & 16,75 & 19,51 & 8,20 & 27,0 & 20,5 & 4,1 & 16,60 \\
Sonchus oleraceus & 0,28 & 0 & 0,06 & 0 & 0,10 & 0 & 0 & 0,27 & 0,10 \\
Galinsoga parviflora & 5,08 & 0,70 & 1,87 & 4,02 & 9,45 & 9,97 & 0 & 1,1 & 4,0 \\
Ipomea spp. & 0,28 & 0,15 & 0,36 & 0 & 0 & 0 & 0,2 & 0 & 0,1 \\
Euphorbia heterophylla & 0,85 & 1,0 & 1,20 & 0,44 & 2,45 & 2,05 & 0 & 1,9 & 1,2 \\
Raphanus raphanistrum & 0,85 & 0,32 & 4,22 & 2,71 & 1,60 & 0,14 & 2,9 & 0,27 & 1,6 \\
Amaranthus retroflexus & 0 & 0,38 & 2,0 & 0,96 & 0 & 0,58 & 1,1 & 0 & 0,6 \\
\hline \multicolumn{1}{|c|}{ SUBTOTAL (1) } & 42,90 & 56,85 & 65,86 & 71,04 & 59,83 & 69,06 & 71,50 & 53,40 & 61,30 \\
\hline Digitaria horizontalis & 15,0 & 40,6 & 1,20 & 13,90 & 24,76 & 22,60 & 28,5 & 42,0 & 23,6 \\
Brachiaria plantaginea & 42,1 & 2,54 & 31,70 & 15,04 & 12,43 & 6,30 & 0 & 4,33 & 14,3 \\
Eleusine indica & 0 & 0 & 1,20 & 0 & 3,0 & 2,05 & 0 & 0,27 & 0,8 \\
\hline \multicolumn{1}{|c|}{ SUBTOTAL (2) } & 57,1 & 43,15 & 34,14 & 28,96 & 40,17 & 30,97 & 28,50 & 46,60 & 38,7 \\
\hline TOTAL (1+2) & 100 & 100 & 100 & 100 & 100 & 100 & 100 & 100 & 100 \\
\hline
\end{tabular}

Pelos resultados obtidos, verifica-se que o período em que a cultura do feijoeiro e as plantas daninhas podem conviver antes que a interferência se instale de maneira a reduzir significativamente a produção (PAI) é até o estádio V4, sendo teoricamente o final do PAI a época ideal para o primeiro controle das infestantes. No entanto, na prática esse período não pode ser considerado, pois a cultura e/ou as plantas daninhas podem ter atingido um 
estádio de desenvolvimento que inviabiliza o uso de práticas de controle; assim, todas as medidas de controle devem ser realizadas no máximo até o estádio fenológico V4. Da emergência do feijoeiro até o estádio R6 corresponde ao período em que a cultura deve ficar livre da presença da comunidade infestante, a fim de que a sua produção não seja influenciada negativamente (PTPI); na prática, este é o período que as capinas ou o efeito residual dos herbicidas devem abranger, pois as infestantes que emergirem nesse período, em determinada época do ciclo da cultura, terão atingido um estádio de desenvolvimento tal que promoverão interferência, reduzindo significativamente a produção.

\section{LITERATURA CITADA}

BLACKSHAW, R. E. Hairy Nightshade (Solanum sarrachoides) interference in dry beans (Phaseolus vulgaris L.). Weed Sci., v. 39, n. 1, p. 39-48, 1991.

BLEASDALE, J. K. A. Studies on plant competition. In: HARPER, J. L. (Ed.). The biology of weeds. Oxford, Backwell Scientific Publication, 1960. p. 133-142.

CERNA, B. L. Determinación del período crítico de competencia de las malezas com el frijol (Phaseolus vulgaris L.) "Muy Finca" en el invierno. Turrialba, v.33, n. 3, p.328-332, 1983.

CHISAKA, H. Weed damage to crops: yield loss due to weed competition. In: FRYER, J. D.; MATSUNAKA, S. (Eds.) Integrated control of weeds. Tokyo: Japan Scientific Societies Press, 1977. p. 1-16.

FANCELLI, L. A.; DOURADO NETO, D. Manejo de plantas daninhas. In: FANCELLI, L. A.; DOURADO NETO, D. (Eds.). Produção de milho. Piracicaba: 2000. p. 183-207.

FERNANDEZ, F.; GEPTS. P.; LOPES, M. Etapas de desarollo de la planta de frijol comum. Cali: Centro Nacional de Agricultura Tropical, 1982. 26 p.

KRAMM, M. V. E. et al. Efeitos da competição com plantas daninhas sobre a cultura do feijão (Phaseolus vulgaris L.).

Revista Ceres, v. 37, p. 345-361, 1990.

KRANZ, W. M. et al. Efeitos em cultivares de feijão (Phaseolus vulgaris L.) da competição com ervas daninhas. In: REUNIÃO NACIONAL DE PESQUISA DE ARROZ E FEIJÃO, 1., 1982, Goiânia. Anais ... Goiânia: 1982. p. 224225.

Planta Daninha, Viçosa-MG, v.20, n.2, p.213-220, 2002
MALIK, V. S.; SWANTON, C. J.; MICHAELS, T. E. Interaction of white bean (Phaseolus vulgaris L.) cultivars, row spacing and seedling density with annual weeds. Weed Sci., v. 41, n. 1, p. 62-68, 1993.

NEARY, P. E.; MAJEK, B. A. Commom cocklebur (Xanthium strumarium) interference in snap beans (Phaseolus vulgaris L.). Weed Technol., v. 4, n. 4, p. 743 748, 1990.

NGOUAJIO, M.; FOKO, J.; FOUEJIO, D. The critical period of weed control in commom bean (Phaseolus vulgaris L.) in Cameroon. Crop Protec., v. 16, n. 2, p. 127-133, 1997.

PITELLI, R. A. Interferências de plantas daninhas em culturas agrícolas. Inf. Agropec., v. 11, n. 129, p. 16-27, 1985.

PITELLI, R. A.; DURIGAN, J. C. Terminologia para períodos de controle e de convivência de plantas daninhas em culturas anuais e bianuais. In : CONGRESSO BRASILEIRO DE HERBICIDAS E PLANTAS DANINHAS, 15., 1984, Belo Horizonte. Resumos... Piracicaba: SBHED, 1984. p. 37.

RADOSEVICH, S. R.; HOLT, J. S. Weed ecology: Implications for vegetation management. New York, John Wiley \& Sons, 1984. 263 p.

RODRIGUEZ, M. M. A.; FAIGUENBAUM, H. Capacidad competitiva de frejol (Phaseolus vulgaris L.), maravilha (Helianthus annus) y papa (Solanum tuberosum) frente a las malezas y periodo critico de competencia. Simiente, v. 55, n. 112 , p. 40,1985

TIVELLI, S. W.; IAMAUTI, M. T.; MINAMI, K. Avaliação do período de matocompetição para feijão - vagem (Phaseolus vulgaris L.) cv. Macarrão. Solo, v. 79, p. 33-36, 1987.

VELINI, E. D. Interferência entre plantas daninhas e cultivadas. In: SIMPÓSIO SOBRE HERBICIDAS E PLANTAS DANINHAS, 1., 1997, Dourados. Resumos... Dourados, 1997, p. 29-49.

WILLIAN, R.D. Competição entre a tiririca (Cyperus rotundus L.) e o feijoeiro (Phaseolus vulgaris L.). R. Ceres, v. 20, n. 112, p. 424-432, 1973.

WOOLLEY, B. L. et al. The critical period of weed control in white bean (Phaseolus vulgaris L.). Weed Sci., v. 41, n. 2, p. 180-184, 1993.

ZOLLINGER, R. K.; KELLS, J. J. Perennial sowthistle (Sonchus arvensis) interference in soybean (Glycine max L.) and dry edible bean (Phaseolus vulgaris L.). Weed

Technol., v. 7, n. 1, p. 52-57, 1993. 